\title{
Comparison of the intermediate distance of a trifocal IOL with an extended depth-of-focus IOL
}

Citation for published version (APA):

Webers, V. S. C., Bauer, N. J. C., Saelens, I. E. Y., Creten, O. J. M., Berendschot, T. T. J. M., van den Biggelaar, F. J. H. M., \& Nuijts, R. M. M. A. (2020). Comparison of the intermediate distance of a trifocal IOL with an extended depth-of-focus IOL: results of a prospective randomized trial. Journal of Cataract and Refractive Surgery, 46(2), 193-203. https://doi.org/10.1097/j.jcrs.0000000000000012

Document status and date:

Published: 01/02/2020

DOI:

10.1097/j.jcrs.0000000000000012

Document Version:

Publisher's PDF, also known as Version of record

Document license:

Taverne

Please check the document version of this publication:

- A submitted manuscript is the version of the article upon submission and before peer-review. There can be important differences between the submitted version and the official published version of record.

People interested in the research are advised to contact the author for the final version of the publication, or visit the DOI to the publisher's website.

- The final author version and the galley proof are versions of the publication after peer review.

- The final published version features the final layout of the paper including the volume, issue and page numbers.

Link to publication

\footnotetext{
General rights rights.

- You may freely distribute the URL identifying the publication in the public portal. please follow below link for the End User Agreement:

www.umlib.nl/taverne-license

Take down policy

If you believe that this document breaches copyright please contact us at:

repository@maastrichtuniversity.nl

providing details and we will investigate your claim.
}

Copyright and moral rights for the publications made accessible in the public portal are retained by the authors and/or other copyright owners and it is a condition of accessing publications that users recognise and abide by the legal requirements associated with these

- Users may download and print one copy of any publication from the public portal for the purpose of private study or research.

- You may not further distribute the material or use it for any profit-making activity or commercial gain

If the publication is distributed under the terms of Article $25 \mathrm{fa}$ of the Dutch Copyright Act, indicated by the "Taverne" license above, 


\title{
Comparison of the intermediate distance of a trifocal IOL with an extended depth-of-focus IOL: results of a prospective randomized trial
}

\author{
Valentijn S.C. Webers, MD, Noel J.C. Bauer, MD, PhD, Isabelle E.Y. Saelens, MD, PhD, Onne J.M. Creten, MD, \\ Tos T.J.M. Berendschot, PhD, Frank J.H.M. van den Biggelaar, PhD, Rudy M.M.A. Nuijts, MD, PhD
}

Purpose: To compare visual outcomes, reading ability, and visual quality between the Symfony extended depth-of-focus intraocular lens (IOL) and the trifocal AT LISA tri 839MP IOL.

Setting: University Eye Clinic Maastricht, The Netherlands.

Design: Prospective randomized controlled trial.

Methods: Patients were randomly assigned to bilateral Symfony IOL or AT LISA tri 839MP IOL implantation. The primary outcome measure was uncorrected intermediate visual acuity (UIVA measured at $66 \mathrm{~cm})$. Secondary outcomes included uncorrected distance visual acuity (UDVA), uncorrected near visual acuity (UNVA), reading ability, and comparison of defocus curves, contrast sensitivity, optical adverse effects, and quality of vision.

Results: The study enrolled 60 eyes of 30 patients. The mean UIVA was $-0.02 \pm 0.03(\mathrm{SD})$ vs $0.01 \pm 0.03$ logarithm of the minimal angle of resolution (logMAR) in the Symfony and AT LISA tri 839MP groups, respectively $(P=.047)$. The UDVA was $0.01 \pm 0.12$ and $-0.05 \pm$ $0.07 \operatorname{logMAR}(P=.11)$ and the UNVA was $0.09 \pm 0.05$ and $0.04 \pm$ $0.07 \operatorname{logMAR}(P=.052)$ in the Symfony and AT LISA tri 839MP groups, respectively. Reading ability was similar in both groups at $40 \mathrm{~cm}$ and $66 \mathrm{~cm}(P=.87$ and $P=.14$, respectively). Less than $10 \%$ of patients in both groups experienced disabling glare. Patients experienced disabling halos in the AT LISA tri $839 \mathrm{MP}$ group compared to the Symfony group in $39 \%$ and $21 \%$ of cases, respectively $(P=.12)$. The mean score for visual functioning was $88.0 \pm 14.1 \mathrm{n}$ the trifocal group and $88.2 \pm 10.9$ for the EDOF group $(P=.96)$.

Conclusions: The UIVA was better in the Symfony group than in the AT LISA tri 839MP group. No significant differences were seen in the binocular UNVA and UDVA, contrast sensitivity, reading ability, incidence of photopic phenomena, and patient satisfaction.

J Cataract Refract Surg 2020; 46:193-203 Copyright @ 2020 Published by Wolters Kluwer on behalf of ASCRS and ESCRS
S ince the introduction of intraocular lenses (IOLs) in the treatment of cataract, the remedy for the postoperative loss of accommodation of the human eye has been an important topic of ongoing research. Bifocal IOLs provided an increased spectacle independence for reading when compared with a monofocal IOL. ${ }^{1,2}$ However, bifocal IOLs have limitations for performance at the intermediate distance. ${ }^{3}$ With the increased use of computers and tablets at the intermediate distance nowadays, trifocal IOLs were introduced that also provide good quality intermediate vision. Multiple trifocal IOL studies have shown a higher spectacle independence compared with bifocal and monofocal IOLs. ${ }^{3}$ However, some of the major side effects of bilateral trifocal or bifocal IOL implantation are the incidence of photopic phenomena (eg, halos and glare) and the reduced visual acuity under mesopic circumstances compared with bilateral monofocal IOL implantation. ${ }^{1-5}$

A few years ago, the TECNIS Symfony Extended Range of Vision ZXR00 IOL (Abbott Medical Optics, Inc.) was introduced to the armamentarium of presbyopia-correcting IOLs. According to the manufacturer, this IOL is theoretically providing a continuous range of high-quality vision for far, intermediate, and near distances with a low incidence of halos and glare comparable to monofocal IOLs under different light conditions. ${ }^{6-8}$

The purpose of this prospective randomized study was to compare a commonly used trifocal IOL, the AT LISA tri 839MP (Carl Zeiss Meditec AG), and the TECNIS Symfony

Submitted: June 14, 2018 | Final revision submitted: September 8, 2019 | Accepted: September 13, 2019

From the University Eye Clinic Maastricht, Maastricht University Medical Center (Webers, Bauer, Saelens, Creten, Berendschot, van den Biggelaar, Nuijts), Maastricht, and Leiden University Medical Centre (Webers), Leiden, The Netherlands.

Supported by a grant from Abbott Laboratories, Santa Ana, USA.

Corresponding author: Valentijn S.C. Webers, MD, University Eye Clinic Maastricht, Maastricht University Medical Center+, P.O. Box 5800, 6202 AZ Maastricht, The Netherlands. Email: valentijn.webers@mumc.nl. 


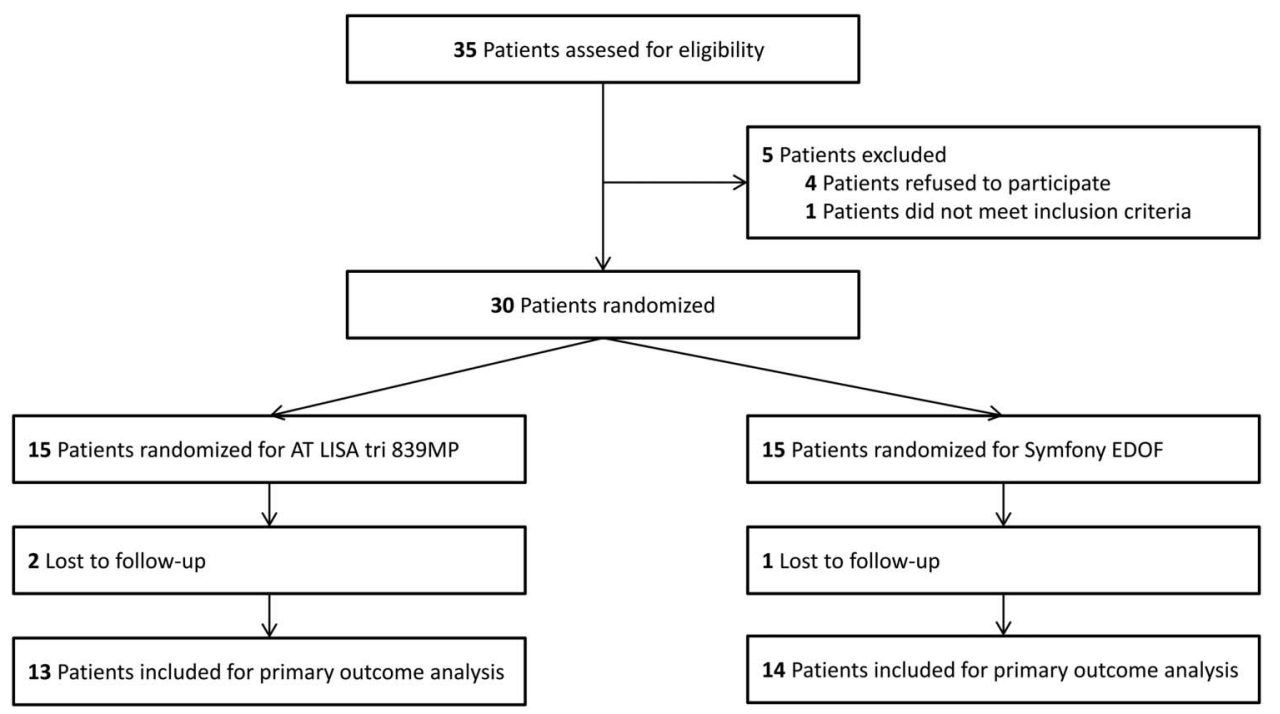

Figure 1. Randomization figure.

Extended Range of Vision ZXR00 IOL in terms of visual and refractive outcomes and analyze spectacle independence, optical side effects, and complications.

\section{METHODS}

Patients scheduled for cataract surgery and desiring spectacle independence were recruited from the Maastricht University Eye Clinic. Patients were randomized for bilateral implantation of the AT LISA tri 839MP IOL (AT LISA tri 839MP group) or blended implantation of the Symfony Extended Range of Vision ZXR00 IOL (Symfony group). The study protocol was approved by the ethics committee of the Maastricht University Medical Center. The study procedures were performed in accordance with the principles of the Declaration of Helsinki. The study protocol can be found at https://clinicaltrials.gov (identifier: NCT03117426). ${ }^{\mathrm{A}}$

The main inclusion criteria were bilateral cataract, expected postoperative astigmatism $\leq 1.00$ diopters (D), and age 21 years or older. Exclusion criteria were irregular corneal astigmatism, previous intraocular or corneal surgery, Fuchs endothelial dystrophy, age-related macular degeneration, glaucoma, macular disease, and diabetic retinopathy.

Intraocular Lens Characteristics and Calculation

The AT LISA tri 839MP is a preloaded IOL with a single-piece diffractive trifocal design and made of hydrophilic acrylic with a hydrophobic surface. Based on theoretical calculation on the diffractive profile, the IOL has a light distribution of $50 \%, 20 \%$, and $30 \%$ between far, intermediate, and near foci, respectively. It provides additions of $+3.33 \mathrm{D}$ and $+1.66 \mathrm{D}$ for near $(40 \mathrm{~cm})$ and intermediate $(80 \mathrm{~cm})$ vision, respectively. The IOL has a $6.0 \mathrm{~mm}$ optic with an overall length of $11.0 \mathrm{~mm}$, a central trifocal zone over a diameter of $4.34 \mathrm{~mm}$, and a peripheral bifocal zone from 4.34 to $6.0 \mathrm{~mm}$. The dioptric power ranges from 0.0 to $+32.0 \mathrm{D}$ in $0.5 \mathrm{D}$ increments.

The TECNIS Symfony ZRX00 is an aspheric biconvex hydrophobic acrylic IOL with a $6.0 \mathrm{~mm}$ optic and an $13.0 \mathrm{~mm}$ overall diameter. The IOL is designed with a proprietary method based on a combination of refractive and diffractive technologies for providing extended depth of focus and, therefore, extended range of vision with combined correction of spherical and chromatic aberration for contrast sensitivity enhancement. ${ }^{\mathrm{B}}$ Nevertheless, two main foci can be assigned: a distance focus and an intermediate focus with an addition of $+1.75 \mathrm{D}$. $^{8}$ The IOL is available in powers from +5.0 to $+34.0 \mathrm{D}$ in $0.5 \mathrm{D}$ increments.
For both IOLs, the Sanders-Retzlaff-Kraff formula was used for the calculation of the IOL power into the capsular bag using optical biometry (either IOLMaster series 500 or 700, Carl Zeiss Meditec). The optimized A-constants used were 119.1 for the Symfony IOL and 118.9 for the AT LISA tri 839MP IOL. In the AT LISA tri 839MP IOL group, emmetropia was targeted for postoperative mean refractive spherical equivalent (MRSE); in the Symfony group, the so-called micromonovision, with the dominant eye aimed to be emmetropic and the nondominant eye to be $-0.5 \mathrm{D}$ in MRSE.

\section{Surgical Technique}

All surgeries in this study were performed by 1 of 3 experienced surgeons (R.M.M.A.N., N.J.C.B., O.J.M.C.). In all eyes, a standard divide-and-conquer phacoemulsification technique or femtosecond laser-assisted cataract surgery was performed using a $2.2 \mathrm{~mm}$ clear corneal incision. In eyes with preexistenting corneal astigmatism of 1.00 to $1.50 \mathrm{D}$, femtosecond laser-assisted arcuate incisions (LenSx, Alcon Laboratories, Inc.) were allowed to reduce the expected postoperative astigmatism within the desired range. Main incisions on the steep axis were performed in eyes with against-the-rule astigmatism between $0.75 \mathrm{D}$ and $1.00 \mathrm{D}$ to prevent increased postoperative residual astigmatism.

\begin{tabular}{|l|c|c|}
\hline \multicolumn{3}{|c|}{ Table 1. Preoperative patient characteristics. } \\
\hline & $\begin{array}{c}\text { AT LISA } \\
\text { Tri 839 MP } \\
\text { Parameter }\end{array}$ & $\begin{array}{c}\text { Symfony } \\
\text { ZXR00 EDOF } \\
(\mathbf{n}=\mathbf{1 3})\end{array}$ \\
\hline Age (y) & & \\
Mean \pm SD & $70.38 \pm 6.08$ & $67.57 \pm 12.21$ \\
Range & 60,79 & 37,79 \\
Mean binocular CDVA & $0.21 \pm 0.12$ & $0.16 \pm 0.17$ \\
$\quad$ (logMAR) \pm SD & $-0.91 \pm 2.95$ & $0.98 \pm 2.73$ \\
Mean MRSE (D) \pm SD & $23.98 \pm 1.73$ & $23.13 \pm 1.71$ \\
Mean axial length (mm) $\pm S D$ & $-0.74 \pm 0.42$ \\
Mean corneal astigmatism (D) & $-0.81 \pm 0.46$ & \\
$\quad \pm$ SD & $5(19)$ & $1(4)$ \\
Femtosecond laser arcuate & & $2(7)$ \\
$\quad$ incisions, $n$ (\%) & $1(4)$ & \\
Temporal main incision, $n(\%)$ & & \\
\hline
\end{tabular}

CDVA = corrected distance visual acuity; EDOF = extended depth of focus; $\mathrm{MRSE}=$ manifest refraction spherical equivalent 
Table 2. Postoperative refractive outcomes and uncorrected visual acuity at near, intermediate, and far.

\begin{tabular}{|c|c|c|c|c|}
\hline \multirow[b]{2}{*}{ Parameter } & \multirow{2}{*}{$\begin{array}{c}\text { AT LISA Tri } 839 \text { MP }(n=13) \\
\text { Both Eyes Combined }\end{array}$} & \multicolumn{2}{|c|}{ Symfony ZXR00 EDOF ( $n=14)$} & \multirow[b]{2}{*}{$P$ Value } \\
\hline & & Dominant Eye & Nondominant Eye & \\
\hline \multicolumn{5}{|l|}{ Spherical error (D) } \\
\hline Mean \pm SD & $0.40 \pm 0.23$ & $0.07 \pm 0.50$ & $-0.25 \pm 0.56$ & - \\
\hline Range & $0.00,0.75$ & $-1.25,0.75$ & $-1.50,0.50$ & \\
\hline \multicolumn{5}{|l|}{ Residual astigmatism (D) } \\
\hline Mean \pm SD & $-0.50 \pm 0.43$ & $-0.63 \pm 0.41$ & $-0.70 \pm 0.58$ & - \\
\hline Range & $-1.50,0.00$ & $-1.50,0.00$ & $-2.00,0.00$ & \\
\hline \multicolumn{5}{|l|}{ MRSE (D) } \\
\hline Mean $\pm S D$ & $0.13 \pm 0.32$ & $-0.24 \pm 0.51$ & $-0.60 \pm 0.60$ & - \\
\hline Range & $-0.50,0.75$ & $-1.75,0.38$ & $-2.13,0.25$ & \\
\hline \multicolumn{5}{|l|}{ Mean photopic \pm SD } \\
\hline Binocular UDVA @ 4 m (logMAR) & $-0.05 \pm 0.07$ & \multicolumn{2}{|c|}{$0.01 \pm 0.12$} & .11 \\
\hline Binocular UIVA @ 66 cm (logMAR) & $0.01 \pm 0.03$ & \multicolumn{2}{|c|}{$-0.02 \pm 0.03$} & .047 \\
\hline Binocular UNVA @ 40 cm (logMAR) & $0.04 \pm 0.07$ & \multicolumn{2}{|c|}{$0.09 \pm 0.05$} & .052 \\
\hline \multicolumn{5}{|l|}{ Mean mesopic \pm SD } \\
\hline Binocular UDVA @ 4 m (logMAR) & $0.08 \pm 0.10$ & \multicolumn{2}{|c|}{$0.11 \pm 0.11$} & .48 \\
\hline Binocular UIVA @ 66 cm (logMAR) & $0.14 \pm 0.09$ & \multicolumn{2}{|c|}{$0.10 \pm 0.05$} & .12 \\
\hline Binocular UNVA @ 40 cm (logMAR) & $0.21 \pm 0.10$ & \multicolumn{2}{|c|}{$0.20 \pm 0.15$} & .87 \\
\hline
\end{tabular}

EDOF = extended depth of focus; logMAR = logarithm of the minimum angle of resolution; MRSE = manifest refraction spherical equivalent; UDVA = uncorrected distance visual acuity; UIVA = uncorrected intermediate visual acuity; UNVA = uncorrected near visual acuity

\section{Randomization}

Consecutive patients were randomly assigned to the Symfony or the AT LISA tri 839MP group. Block randomization was performed with a block size of 4 patients to reduce bias and achieve balance in allocation of participants in both treatment arms. The patient and the investigator performing the postoperative examinations were masked to the treatment allocation. At the 3month follow-up, the randomization was disclosed.

\section{Preoperative Assessment}

Preoperatively, each patient had a full ophthalmologic evaluation using slitlamp biomicroscopy, fundoscopy, and intraocular pressure measurement. Automated keratometry (partial coherence interferometry based), optical biometry (IOLMaster series 500 or 700), pupillometry (P2000 SA pupillometer, Procyon Instruments Ltd.), and corneal topography (Pentacam, Oculus Optikgeräte $\mathrm{GmbH}$ ) were performed before surgery.

\section{Postoperative Assessment}

At all postoperative visits ( 1 week, 1 month, and 3 months), the monocular uncorrected distance visual acuity (UDVA) and corrected distance visual acuity (CDVA) were measured using Early Treatment Diabetic Retinopathy Study charts at $4 \mathrm{~m}$.
Patients were asked to start reading the charts at the smallest row on which all letters were easily distinguishable, proceeding until no letters on a row were read correctly. The correct number of letters was noted and transferred into logarithm of the minimal angle of resolution ( $\log M A R)$ values for further analysis. In addition, at the 1-month and 3-month postoperative visits, the binocular UDVA and CDVA and binocular uncorrected near visual acuity (UNVA, $40 \mathrm{~cm}$ ) and intermediate visual acuity (UIVA, $66 \mathrm{~cm}$ ) were measured. At the final follow-up visit, all visual acuity measurements were obtained under photopic ( $\geq 80 \mathrm{~cd} / \mathrm{m}^{2}$ luminance) and mesopic $\left(\leq 10 \mathrm{~cd} / \mathrm{m}^{2}\right.$ luminance) conditions. Furthermore, binocular defocus curves were obtained at the final visit in photopic and mesopic conditions. During the defocus test, increments of 0.50 $\mathrm{D}$ were added (range -4.0 to $+2.0 \mathrm{D}$ ) to the CDVA in both eyes to produce defocus.

\section{Reading Ability}

The Salzburg Reading Desk (Version 1.0, SRD Vision LLC) was used to measure the reading ability at near and intermediate distances. This device has been described in several studies and allows for measuring reading acuity in logMAR and reading speed in words per minute at a predetermined or subjectively preferred
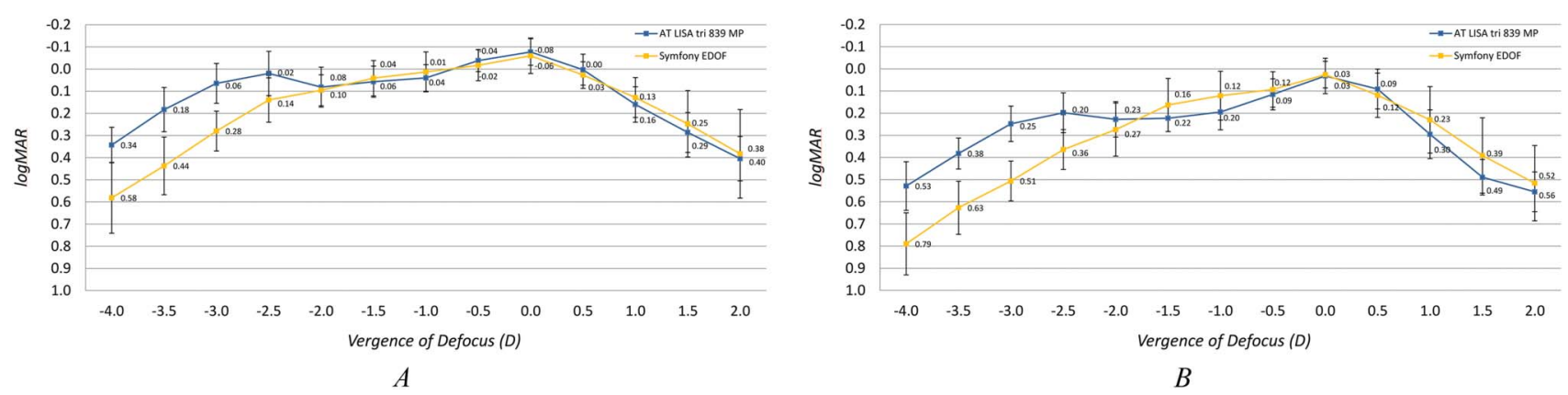

Figure 2. Defocus curves. $A$, Defocus curve for both IOLs in photopic conditions. $B$, Defocus curve for both IOLs in mesopic conditions $(\mathrm{IOL}=$ intraocular lens). 
Table 3. Reading ability at near and intermediate distance under photopic and mesopic conditions.

\begin{tabular}{|c|c|c|c|c|c|}
\hline \multirow[b]{2}{*}{ Parameter } & \multicolumn{2}{|c|}{ At Testing Distance ${ }^{*}$} & \multicolumn{2}{|c|}{ At Preferred Distance } & \multirow{2}{*}{$\begin{array}{l}\text { Preferred Distance } \\
\text { (cm) }\end{array}$} \\
\hline & LogMAR & WPM & LogMAR & WPM & \\
\hline \multicolumn{6}{|l|}{ Photopic conditions } \\
\hline AT LISA tri $839 \mathrm{MP}$ & 0.08 & 114 & 0.07 & 116 & 36 \\
\hline $\begin{array}{l}\text { Symfony ZXROO } \\
\text { EDOF }\end{array}$ & 0.08 & 116 & 0.07 & 107 & 41 \\
\hline $\begin{array}{l}P \text { value } \\
\text { Intermediate distance } \dagger\end{array}$ & .87 & .77 & .99 & .29 & - \\
\hline AT LISA tri $839 \mathrm{MP}$ & 0.10 & 111 & 0.05 & 96 & 75 \\
\hline $\begin{array}{l}\text { Symfony ZXROO } \\
\text { EDOF }\end{array}$ & 0.07 & 125 & 0.04 & 117 & 64 \\
\hline$P$ value & .14 & .34 & .71 & .09 & - \\
\hline $\begin{array}{l}\text { Mesopic conditions } \\
\text { Near distance }\end{array}$ & & & & & \\
\hline AT LISA tri 839 MP & 0.33 & 107 & 0.31 & 113 & 35 \\
\hline $\begin{array}{l}\text { Symfony ZXROO } \\
\text { EDOF }\end{array}$ & 0.32 & 105 & 0.31 & 105 & 40 \\
\hline $\begin{array}{l}P \text { value } \\
\text { Intermediate distance } †\end{array}$ & .77 & 086 & .92 & .58 & - \\
\hline AT LISA tri $839 \mathrm{MP}$ & 0.30 & 108 & 0.27 & 99 & 70 \\
\hline $\begin{array}{l}\text { Symfony ZXROO } \\
\text { EDOF }\end{array}$ & 0.28 & 111 & 0.24 & 95 & 63 \\
\hline$P$ value & .82 & .80 & .34 & .70 & - \\
\hline
\end{tabular}

EDOF = extended depth of focus; logMAR = logarithm of the minimum angle of resolution; WPM = words per minute (reading threshold 80 WPM)

"Testing distance $40 \mathrm{~cm}$ for near and $66 \mathrm{~cm}$ for intermediate.

reading distance. ${ }^{9-14}$ The device consists of a high-resolution monitor on which log-scaled Colenbrander sentences are displayed, and a laptop computer on which the operating software is displayed. The reading distance is measured by 2 infrared video cameras. A microphone is used to determine the reading time and reading speed. The Colenbrander sentences are presented in progressively smaller print sizes, and different photopic and mesopic conditions can be simulated. A reading speed of a minimum of 80 words per minute is accepted.

A fixed distance of $66 \mathrm{~cm}$ and $40 \mathrm{~cm}$ was used for measuring intermediate and near vision, respectively. Both distances were tested under photopic $\left(100 \%\right.$ contrast and $100 \mathrm{~cd} / \mathrm{m}^{2}$ luminance) and mesopic ( $30 \%$ contrast and $20 \mathrm{~cd} / \mathrm{m}^{2}$ luminance) conditions. In addition, patients were asked to freely choose a patient-preferred reading distance for both intermediate and near vision.

\section{Contrast Sensitivity}

The CSV-1000 system (Vector Vision Inc.) was used to measure contrast sensitivity under photopic and mesopic conditions.
Special spectacles with mesopic lenses (Vector Vision Inc.) were used to simulate mesopic circumstances. Binocular contrast sensitivity at $4 \mathrm{~m}$ was obtained at the 3 -month follow-up with correcting spectacles if necessary.

\section{Spectacle Independence, Photopic Phenomena, and Quality of Vision}

Postoperative validated questionnaires at 3 months were obtained to evaluate the percentage of patients with spectacle independency, the incidence of photopic phenomena (eg, halos and glare), and vision-related quality of life (VQOL). Spectacle dependence was expressed by a frequency score varying from 1 (always) to 5 (never). The validated Visual Functioning Questionnaire (VF-14) determined the amount of trouble patients had with vision-related daily activities (eg, reading and driving) and ranged from 0 to 100 (higher scores meaning better functioning). ${ }^{15,16}$ The VQOL was expressed by a VCM1 (Core Module) score, ranging from 0 (best possible VQOL) to 5 (worst possible VQOL). ${ }^{17}$
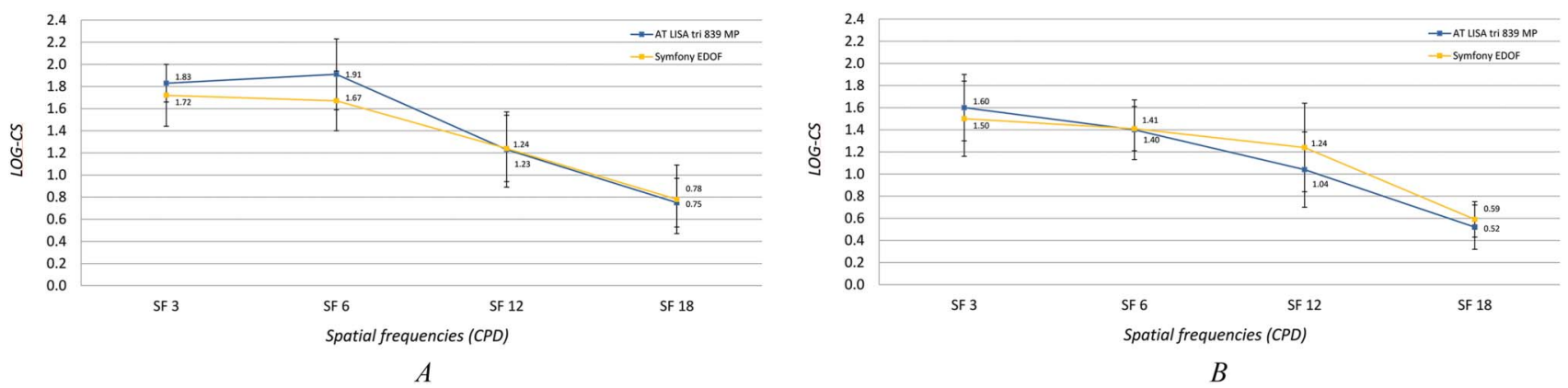

Figure 3. Contrast sensitivity charts. $A$, Contrast sensitivity for both IOLs in photopic conditions. $B$, Contrast sensitivity for both IOLs in mesopic conditions. $\mathrm{CS}=$ contrast sensitiviy (cpd = cycles per degree; $\mathrm{IOL}=$ intraocular lens). 


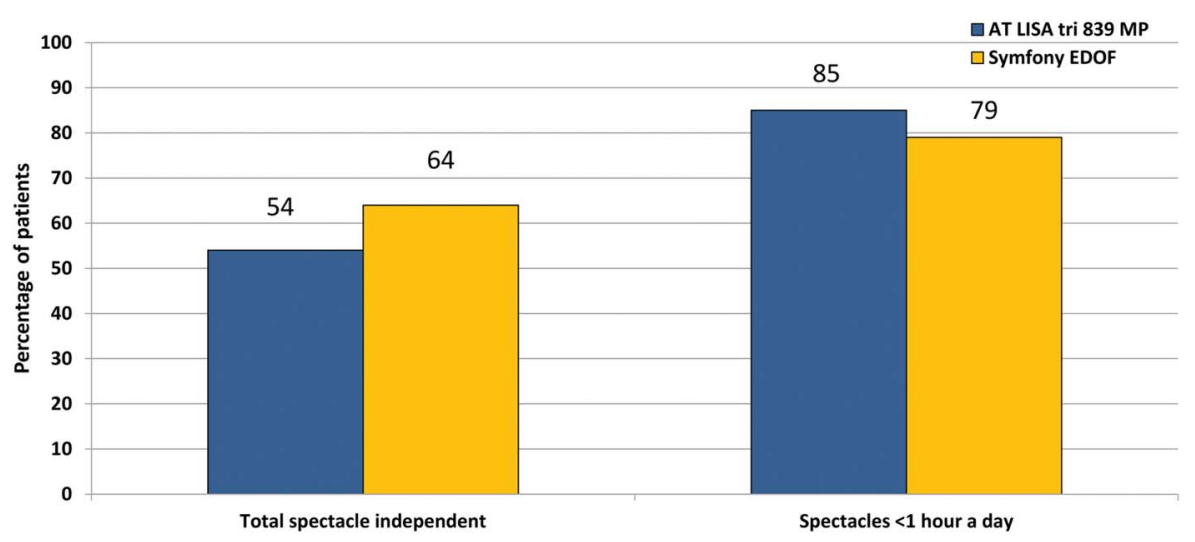

Figure 4. Spectacle independence. Percentage of patients in both groups with total spectacle independence after bilateral surgery and the percentage of patients who only required spectacles for less than 1 hour a day (EDOF = extended depth of focus).

\section{Sample Size}

The calculation of the sample size was based on the primary outcome of binocular uncorrected visual acuity at the intermediate distance $(66 \mathrm{~cm})$. In a prospective study with a binocular AT LISA tri $839 \mathrm{MP}$ IOL, a binocular uncorrected visual acuity at the intermediate distance $(66 \mathrm{~cm})$ of $0.08 \pm 0.10 \log$ MAR was found. ${ }^{18}$ To find a clinically significant difference between the 2 groups, a difference of $0.14 \log$ MAR (difference of 7 letters on the Early Treatment Diabetic Retinopathy Study chart) was assumed. Based on these assumptions ( $\mathrm{alpha}=0.05$ and power $=0.9$ ), 12 patients were required in each group. Assuming a drop out of less than $20 \%$ on the primary outcome measure, 30 patients needed to be included.

\section{Statistical Analysis}

All data were collected in an electronic data capture system for medical research (Castor EDC, CIWIT B.V.) and transferred to SPSS for Windows software (version 23.0, 2010, IBM Corp.) for data analysis. To evaluate differences between the 2 groups, independent Student $t$ tests was used. Furthermore, paired $t$ tests were used to analyze changes in visual acuities between the preoperative and postoperative visits. If the distribution of variables was not normal, the nonparametric Mann-Whitney $U$ test was used. In all tests, the threshold of statistical significance was assumed equal to a $P$ value of 0.05 .

\section{RESULTS}

A total of 30 patients (60 eyes) were randomly assigned to the Symfony or the AT LISA tri 839MP group (Figure 1). The Symfony group comprised 15 patients (11 women [73\%]) with a mean age of 70 years (range 60 to 79 years). The AT LISA tri 839MP group comprised 15 patients ( 9 women [15\%]) with a mean age of 68 years (range 37 to 79 years). Preoperatively, there were no statistically significant differences in age, binocular CDVA, MRSE, axial length, or corneal astigmatism between both groups (Table 1).
A total of 3 patients were lost to follow-up because of personal reasons, 2 in the AT LISA tri 839MP group and 1 in the Symfony group. Additional intraoperative femtosecond laser-assisted arcuate incisions were performed in 5 eyes (19\%) in the AT LISA tri 839MP group and in 1 eye (4\%) in the Symfony group. Temporal incisions were performed in $4 \%$ $(n=1)$ of eyes in the AT LISA tri 839MP group and in $7 \%$ $(\mathrm{n}=2)$ of eyes in the Symfony group (Table 1$)$.

\section{Visual Acuity and Refraction}

Table 2 shows the achieved refractive outcomes and binocular uncorrected visual acuity at distance, intermediate, and near under photopic and mesopic conditions at the final postoperative visit at 3 months. No significant differences were found in the UDVA and UNVA. A small significant difference was found in UIVA between both groups ( $P=.047$, Mann-Whitney $U$ test $)$ in favor of the Symfony group. A decrease in visual acuity at all distances was seen in both groups when measuring under mesopic vs photopic conditions ( $P \leq .05$, MannWhitney $U$ test). No differences in visual acuity at all distances were seen between groups under mesopic conditions ( $P \geq .05$, Mann-Whitney $U$ test).

At 3 months postoperatively, the mean MRSE was -0.24 $\mathrm{D} \pm 0.51(\mathrm{SD})$ and $-0.60 \pm 0.60 \mathrm{D}$ in the Symfony group for the dominant and nondominant eyes, respectively. The mean MRSE in the AT LISA tri 839MP group was $0.13 \pm$ $0.32 \mathrm{D}$. No significant differences were found in the mean residual astigmatism between both groups $(P \geq .05$, Mann-Whitney $U$ test). A total of $8 \%$ and $11 \%$ of patients had a residual astigmatism of $1.5 \mathrm{D}$ or more in the AT LISA tri 839MP and Symfony groups, respectively.

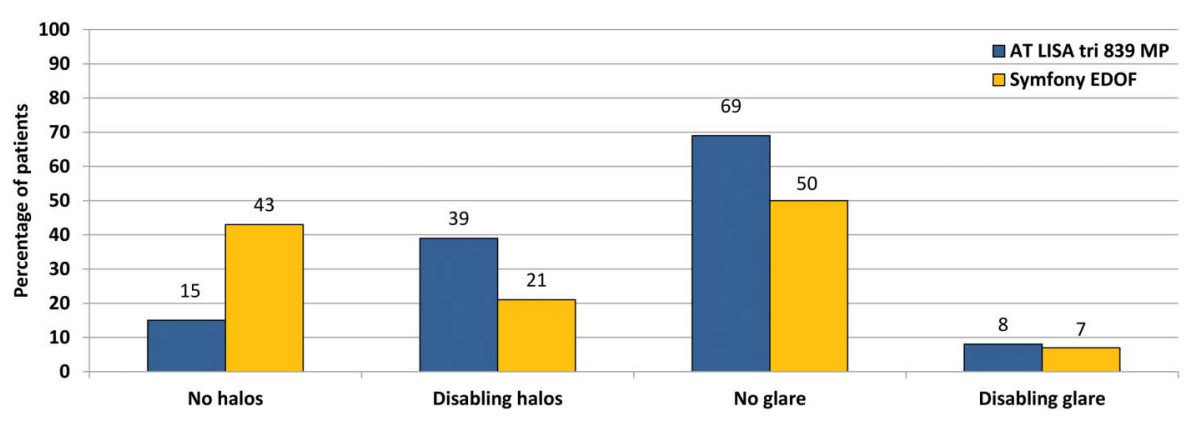

Figure 5. Percentage of patients in both groups experiencing no photopic phenomena (halos or glare) and the percentage of patients experiencing disabling halos and glare (EDOF = extended depth of focus). 
Table 4. Overview of prospective studies reporting clinical outcomes in logMAR after Symfony EDOF IOL implantation.

\begin{tabular}{|c|c|c|c|c|c|c|c|}
\hline \multirow[b]{2}{*}{ Author } & \multirow[b]{2}{*}{ Study Design } & \multirow{2}{*}{$\begin{array}{c}\text { Eyes } \\
\text { (n) }\end{array}$} & \multirow[b]{2}{*}{ MRSE (D) } & \multicolumn{2}{|c|}{ UDVA } & \multicolumn{2}{|c|}{ UIVA } \\
\hline & & & & Distance $(\mathrm{m})$ & LogMAR & Distance $(\mathrm{cm})$ & LogMAR \\
\hline Pedrotti et al. ${ }^{19}$ & Prospective case series & 50 & $-0.27 \pm 0.47$ & 4 & $0.00 \pm 0.09$ & 60 & $0.10 \pm 0.09$ \\
\hline Cochener ${ }^{20}$ & Prospective case series & 224 & $\begin{array}{c}-0.21 \pm 0.38 \\
\text { (dominant) } \\
-0.75 \pm 0.52 \\
\text { (nondominant) }\end{array}$ & 4 & $0.04 \pm 0.11$ & 70 & $0.09 \pm 0.17$ \\
\hline Cochener $^{20}$ & Prospective case series & 585 & $-0.30 \pm 1.13$ & 4 & $0.03 \pm 0.09$ & 70 & $0.13 \pm 0.16$ \\
\hline $\begin{array}{l}\text { Ruiz-Mesa } \\
\text { et al. }{ }^{21}\end{array}$ & Prospective case series & 40 & $-0.19 \pm 0.18$ & 4 & $0.01 \pm 0.02$ & 60 & $0.09 \pm 0.08$ \\
\hline Monaco et al. ${ }^{22}$ & $\mathrm{RCT}$ & 40 & $-0.23 \pm 0.03$ & 4 & $0.00 \pm 0.04$ & 67 & $0.23 \pm 0.07$ \\
\hline Pedrotti et al. ${ }^{23}$ & Prospective case series & 60 & $-0.08 \pm 0.28$ & 4 & $-0.04 \pm 0.09$ & 60 & $0.05 \pm 0.09$ \\
\hline Menucci et al. ${ }^{24}$ & Prospective case series & 40 & $-0.13 \pm 0.61 \mathrm{D}$ & 4 & $-0.04 \pm 0.05$ & 80 & $0.07 \pm 0.07$ \\
\hline Ganesh et al. ${ }^{25}$ & Prospective case series & 50 & $\begin{array}{c}-0.22 \pm 0.37 \mathrm{D} \\
\quad \text { (dominant) } \\
-0.74 \pm 0.44 \mathrm{D} \\
\text { (nondominant) }\end{array}$ & 4 & $-0.04 \pm 0.09$ & 60 & $0.05 \pm 0.09$ \\
\hline Ganesh et al. ${ }^{25}$ & Prospective case series & 50 & $\begin{array}{c}-0.22 \pm 0.37 \mathrm{D} \\
\quad \text { (dominant) } \\
-0.74 \pm 0.44 \mathrm{D} \\
\text { (nondominant) }\end{array}$ & 4 & $-0.04 \pm 0.09$ & 80 & $-0.04 \pm 0.09$ \\
\hline Kohnen et al. ${ }^{26}$ & Prospective case series & 52 & $-0.17 \pm 0.30 \mathrm{D}$ & 4 & $-0.02 \pm 0.07$ & 80 & $0.01 \pm 0.07$ \\
\hline Kohnen et al. ${ }^{26}$ & Prospective case series & 52 & $-0.17 \pm 0.30 \mathrm{D}$ & 4 & $-0.02 \pm 0.07$ & 60 & $0.08 \pm 0.18$ \\
\hline
\end{tabular}

$\mathrm{EDOF}=$ extended depth of focus; $\mathrm{IOL}=$ intraocular lens; logMAR = logarithm of the minimal angle of resolution; $\mathrm{MRSE}=$ mean refraction spherical equivalent; $\mathrm{NA}=$ not available (not reported); RCT = randomized controlled trial; UDVA = uncorrected distance visual acuity; UIVA = uncorrected intermediate visual acuity; UNVA = uncorrected near visual acuity

Figure 2 shows the defocus curves for both groups under photopic and mesopic conditions. The photopic defocus curve showed best visual acuity $(0.02$ and $-0.08 \log M A R)$ at $-2.5 \mathrm{D}$ and $0.0 \mathrm{D}$ for the AT LISA tri $839 \mathrm{MP}$ group. Between these 2 peaks, the visual acuity dropped to 0.08 $\log$ MAR at $-2.0 \mathrm{D}$. In the Symfony group, there was a more continuously increasing visual acuity seen between $-2.5 \mathrm{D}$ and $0.0 \mathrm{D}$, with a best visual acuity of -0.06 $\log$ MAR at $0.0 \mathrm{D}$. Under mesopic conditions, the defocus curve showed a best visual acuity in the AT LISA tri 839MP group of $0.20 \log$ MAR at $-2.5 \mathrm{D}$ and $0.03 \log \mathrm{MAR}$ at $0.0 \mathrm{D}$, with a lowest visual acuity of $0.23 \log$ MAR at $-2.0 \mathrm{D}$. The Symfony group showed a continuously increasing visual acuity between $-1.5 \mathrm{D}$ and $0.0 \mathrm{D}$, with a best visual acuity at $0.0 \mathrm{D}$ of $0.03 \log$ MAR. The AT LISA tri 839MP group scored significantly better from -4.0 to $-2.5 \mathrm{D}(P<.05$, Mann-Whitney $U$ test $)$ compared with the Symfony group.

\section{Reading Ability}

Table 3 demonstrates the reading ability for both groups at different distances measured with the SRD under photopic and mesopic conditions. No significant differences were seen between both groups in reading ability at $40 \mathrm{~cm}, 66 \mathrm{~cm}$, or the preferred distance for near and intermediate distances under photopic conditions $(P \geq .05$, Mann-Whitney $U$ test). The preferred near reading distance was $36 \mathrm{~cm}$ in the AT LISA tri 839MP group, whereas this distance was $41 \mathrm{~cm}$ in the Symfony group. A larger difference was seen at the intermediate distance, with preferred reading distances of
$75 \mathrm{~cm}$ in the AT LISA tri 839MP group and $64 \mathrm{~cm}$ in the Symfony group.

Under mesopic conditions, no differences were found in reading ability at $40 \mathrm{~cm}, 66 \mathrm{~cm}$, or the preferred distance for near and intermediate distances $(P \geq .05$, Mann-Whitney $U$ test). The preferred reading distances in the AT LISA tri $839 \mathrm{MP}$ group were $35 \mathrm{~cm}$ and $70 \mathrm{~cm}$, whereas the preferred reading distances in the Symfony group were $40 \mathrm{~cm}$ and $63 \mathrm{~cm}$ for near and intermediate distances, respectively.

\section{Contrast Sensitivity}

Figure 3 shows the contrast sensitivity for both groups under photopic and mesopic conditions. The mean contrast sensitivity under photopic conditions was $1.43 \pm$ 0.54 and $1.35 \pm 0.47$ for the AT LISA tri $839 \mathrm{MP}$ and Symfony groups, respectively $(P \geq .05)$. No significant difference in contrast sensitivity was noted between the AT LISA tri 839MP and Symfony group under mesopic conditions with mean values of $1.14 \pm 0.50$ vs $1.19 \pm 0.46$, respectively $(P \geq .05)$.

\section{Spectacle Independence, Photopic Phenomena, and Quality of Vision}

Figure 4 shows the percentage of patients achieving total spectacle independency and the percentage of patients using spectacles less than 1 hour a day for specific daily tasks. No statistical significant differences were seen between both groups. More than $50 \%$ of patients were totally spectacle independent 3 months postoperatively. A slightly higher percentage of patients in the Symfony group 
Table 4. Continued.

\begin{tabular}{|c|c|c|c|c|c|c|}
\hline \multicolumn{2}{|c|}{ UNVA } & \multicolumn{2}{|c|}{ Halos (\%) } & \multicolumn{2}{|c|}{ Glare (\%) } & \multirow{2}{*}{$\begin{array}{c}\text { Total } \\
\text { Spectacle } \\
\text { Independence } \\
(\%)\end{array}$} \\
\hline Distance $(\mathrm{cm})$ & LogMAR & Any & Disabling & Any & Disabling & \\
\hline 40 & $0.18 \pm 0.08$ & NA & NA & NA & NA & NA \\
\hline 40 & $0.17 \pm 0.18$ & NA & 4 & NA & 1 & $\leq 81$ \\
\hline 40 & $0.21 \pm 0.16$ & NA & 3 & NA & 2 & $\leq 72$ \\
\hline 40 & $0.17 \pm 0.06$ & NA & NA & NA & NA & 0.9 \\
\hline 40 & $0.02 \pm 0.06$ & 95 & 20 & 90 & 12 & 0.7 \\
\hline 40 & $0.18 \pm 0.10$ & NA & NA & NA & NA & NA \\
\hline 40 & $0.25 \pm 0.08$ & 70 & NA & 50 & NA & 60 \\
\hline 40 & $0.15 \pm 0.11$ & NA & NA & NA & NA & 84 \\
\hline 40 & $0.15 \pm 0.11$ & NA & NA & NA & NA & 84 \\
\hline 40 & $0.22 \pm 0.15$ & 54 & NA & 33 & NA & 71 \\
\hline 40 & $0.22 \pm 0.15$ & 54 & NA & 33 & NA & 71 \\
\hline
\end{tabular}

achieved total spectacle independency compared with the AT LISA tri 839MP group. Eighty-five percent and 79\% of patients needed no spectacles at all or only 1 hour a day in the AT LISA tri 839MP and Symfony groups, respectively.

Figure 5 demonstrates that $43 \%$ of patients in the Symfony group experienced no halos vs $15 \%$ in the AT LISA tri 839MP group $(P=.12)$. Disabling halos (score 4 to 5 on the Likert scale) were reported in almost twice as many patients (39\% vs $21 \%$ ) in the AT LISA tri $839 \mathrm{MP}$ group compared with the Symfony group; however, no statistically significant difference was found $(P=.33)$. More than $50 \%$ of patients in both groups did not report glare, and less than $10 \%$ of patients in both groups experienced disabling glare. Disabling glare ( $8 \%$ vs $7 \%$; $P=.96$ ) was mentioned less often compared with disabling halos $(39 \%$ vs $21 \%$ ) in the AT LISA tri $839 \mathrm{MP}$ and Symfony groups, respectively.

The mean score for visual functioning regarding visionrelated daily activities was $88.0 \pm 14.1$ for the AT LISA tri 839MP group and $88.2 \pm 10.9$ for the Symfony group $(P=.96)$. The VQOL was excellent in both groups, with a mean score of $0.33 \pm 0.42$ for the AT LISA tri $839 \mathrm{MP}$ group and $0.29 \pm 0.55$ for the Symfony group $(P=.81)$.

Ninety-two percent and $93 \%$ of patients for the AT LISA tri 839 and Symfony groups (13 out of 14 patients) would recommend the implanted IOL to family or friends, respectively.

\section{Complications and Adverse Events}

No surgical complications were reported. Postoperatively, neodymium:YAG laser capsulotomy to treat posterior capsule opacification was performed in 1 patient (1 eye) in both groups. After fulfilling all control visits, a total of 3 patients (1 in the AT LISA tri 839MP group and 2 in the Symfony group) underwent laser-assisted subepithelial keratectomy to correct a myopic residual refractive error or residual astigmatism.

\section{DISCUSSION}

The purpose of this study was to compare the clinical outcomes of a commonly used presbyopia-correcting trifocal IOL (AT LISA tri 839MP) vs a novel IOL design with an extended range of vision to correct presbyopia (TECNIS Symfony), with the primary outcome being intermediate vision. At 3 months postoperatively, a significant difference in UIVA was found in favor of the Symfony group. However, it is questionable if this small difference of $0.03 \log$ MAR is clinically relevant. No significant differences were seen in the binocular uncorrected visual acuity at near or distance contrast sensitivity, reading ability under both photopic and mesopic conditions, incidence of photopic phenomena, and patient satisfaction. However, the study was not powered to look at these secondary outcomes. The defocus curves of the Symfony group under photopic conditions showed a more continuous increase in visual acuity between $-2.5 \mathrm{D}$ and $0.0 \mathrm{D}$ compared with the AT LISA tri 839MP group, where 2 distinct peaks at $-2.5 \mathrm{D}$ and $0.0 \mathrm{D}$ were identified.

With the increasing use of computers and tablets at the intermediate distance, the correction and spectacle independence for this distance becomes increasingly important for a broad patient population. The introduction of trifocal IOLs was the first step toward improved uncorrected intermediate vision. However, since the introduction of the extended range of vision IOLs, a new alternative for excellent intermediate vision is available. Because of the design, a continuous optimum vision from far to near could be obtained in combination with a decreased occurrence of photopic phenomena. ${ }^{6-8}$ To our knowledge, no studies are available comparing this extended range of vision IOL design with the commonly used AT LISA tri 839MP IOL for the intermediate distance in a prospective randomized controlled trial.

Table 4 provides an overview of the currently available prospective case series and randomized controlled trials evaluating the TECNIS Symfony IOL. ${ }^{19-26}$ In our study, the primary outcome measure was binocular UIVA at $66 \mathrm{~cm}$. The current literature concerning the Symfony IOL is limited. Most studies report UIVA for distances measured between $60 \mathrm{~cm}$ and $70 \mathrm{~cm}$. Because none of these studies determined the UIVA at $66 \mathrm{~cm}$, the UIVA determined in 


\begin{tabular}{|c|c|c|c|c|c|c|c|}
\hline \multirow[b]{2}{*}{ Author } & \multirow[b]{2}{*}{ Study Design } & \multirow{2}{*}{$\begin{array}{c}\text { Eyes } \\
\text { (n) }\end{array}$} & \multirow[b]{2}{*}{ MRSE (D) } & \multicolumn{2}{|c|}{ UDVA } & \multicolumn{2}{|c|}{ UIVA } \\
\hline & & & & Distance (m) & LogMAR & Distance (cm) & LogMAR \\
\hline Mojzis et al. ${ }^{18}$ & Prospective case series & 60 & $-0.12 \pm 0.39$ & 4 & $-0.03 \pm 0.09$ & 66 & $0.08 \pm 0.10$ \\
\hline Mojzis et al. ${ }^{27}$ & Prospective case series & 120 & $-0.08 \pm 0.39$ & 4 & $0.03 \pm 0.13$ & 80 & $0.11 \pm 0.13$ \\
\hline Mojzis et al. ${ }^{27}$ & Prospective case series & 120 & $-0.08 \pm 0.39$ & 4 & $0.03 \pm 0.13$ & 66 & $0.12 \pm 0.13$ \\
\hline Kretz et al. ${ }^{28}$ & Prospective case series & 100 & -0.08 & 4 & 0.04 & 66 & 0.04 \\
\hline Marques et al. ${ }^{29}$ & Prospective case series & 30 & $-0.02 \pm 0.39$ & 4 & $0.00 \pm 0.01$ & 80 & $0.13 \pm 0.42$ \\
\hline Mendicute et al. ${ }^{30}$ & Prospective case series & 208 & $0.35 \pm 0.28$ & 4 & $0.03 \pm 0.09$ & 80 & $0.10 \pm 0.15$ \\
\hline Kohnen et al..$^{31}$ & Prospective case series & 54 & NA & 4 & $-0.06 \pm 0.10$ & 80 & $0.00 \pm 0.12$ \\
\hline $\begin{array}{l}\text { Bilbao-Calabuig } \\
\text { et al. }^{32}\end{array}$ & Restrospective study & 8564 & $0.26 \pm 0.47$ & 4 & $-0.01 \pm 0.06$ & 80 & $-0.05 \pm 0.14$ \\
\hline Kaymak et al. ${ }^{33}$ & RCT & 26 & $0.29 \pm 0.37$ & 4 & $-0.02 \pm 0.08$ & 70 & $0.12 \pm 0.12$ \\
\hline Kaymak et al. ${ }^{33}$ & $\mathrm{RCT}$ & 26 & $0.29 \pm 0.37$ & 4 & $-0.02 \pm 0.08$ & 80 & $0.10 \pm 0.11$ \\
\hline Mencucci et al. ${ }^{34}$ & Prospective case series & 42 & NA & 4 & $0.00 \pm 0.05$ & 80 & $0.11 \pm 0.07$ \\
\hline Alió et al. ${ }^{35}$ & $\mathrm{RCT}$ & 32 & NA & 4 & $-0.03 \pm 0.07$ & 80 & $0.11 \pm 0.14$ \\
\hline Alió et al. ${ }^{35}$ & $\mathrm{RCT}$ & 32 & NA & 4 & $-0.03 \pm 0.07$ & 70 & $0.14 \pm 0.16$ \\
\hline Menucci et al. ${ }^{24}$ & Prospective case series & 40 & $-0.16 \pm 0.55 \mathrm{D}$ & 4 & $0.00 \pm 0.02$ & 80 & $0.11 \pm 0.07$ \\
\hline Xiamin et al. ${ }^{36}$ & Prospective case series & 50 & NA & 4 & $0.02 \pm 0.09$ & 80 & $0.08 \pm 0.10$ \\
\hline Yang et al. ${ }^{37}$ & Prospective case series & 52 & NA & 4 & $0.05 \pm 0.10$ & 66 & $0.23 \pm 0.12$ \\
\hline
\end{tabular}

$\mathrm{IOL}=$ intraocular lens; logMAR = logarithm of the minimal angle of resolution; MRSE = mean refractive spherical equivalent; $N A=$ not available (not reported); $\mathrm{RCT}$ = randomized controlled trial; UDVA = uncorrected distance visual acuity; UIVA = uncorrected intermediate visual acuity; UNVA = uncorrected near visual acuity

our study at $66 \mathrm{~cm}$ cannot be compared with the current literature. In terms of measurement distance of UDVA $(4 \mathrm{~m})$ and UNVA $(40 \mathrm{~cm})$, several prospective studies are available to compare with our results. ${ }^{19-26}$ The current literature shows an excellent UDVA for the Symfony IOL in nearly all studies (range 0.04 to $-0.04 \log M A R$ ). For UNVA, most studies show a much lower logMAR visual acuity at $40 \mathrm{~cm}$ (range 0.25 to $0.02 \log M A R)$. The present study also showed an excellent UDVA and a slightly better UIVA and UNVA compared with previous studies. ${ }^{19-26}$ In our study, we aimed for micromonovision with the dominant eye to be emmetropic and the nondominant eye to have a slightly myopic MRSE (target $-0.50 \mathrm{D}$ ). Both the dominant and nondominant eyes in our study population achieved a slightly more myopic outcome in terms of MRSE as desired $(-0.24 \mathrm{D}$ and $-0.60 \mathrm{D}$, respectively). We believe that this minor myopic outcome might explain the better UIVA and UNVA compared with the current literature. The study of Cochener ${ }^{20}$ and that of Ganesh et al. ${ }^{25}$ were the only ones aiming for micromonovision with comparable MRSE outcomes. They found a slightly worse UDVA, UIVA (at $60 \mathrm{~cm}$ and $70 \mathrm{~cm}$ ), and UNVA compared with our study. Ganesh et al. ${ }^{25}$ reported a total spectacle independence of $84 \%$. Cochener ${ }^{20}$ noted that $19 \%$ of patients with a micromonovision target still needed additional reading spectacles for specific tasks, whereas $28 \%$ of patients with a bilateral emmetropic target needed additional reading spectacles. In our study, total spectacle independency was $64 \%$, and only $21 \%$ of patients needed spectacle correction for longer than 1 hour a day. Only a few studies reported incidences of halos and glare. Monaco et al. ${ }^{22}$ showed that around $95 \%$ of patients experienced any type of halos, and $20 \%$ of patients experienced disabling halos. In terms of glare, they reported an incidence of $90 \%$ of any form of glare, with $12 \%$ of patients experiencing disabling glare. Cochener ${ }^{20}$ reported only $3 \%$ to $4 \%$ of patients with disabling halos and $1 \%$ to $2 \%$ of patients with disabling glare. Compared with our results, the percentage of disabling halos was comparable to the study of Monaco et $\mathrm{al}^{22}$ The incidence of disabling glare was within $7 \%$ in the range of both studies. ${ }^{20,22}$

Table 5 provides an overview of the currently available prospective case series and randomized controlled trials evaluating the AT LISA tri 839MP IOL. ${ }^{18,27-37}$ In terms of our primary outcome, several studies reported UIVA at $66 \mathrm{~cm} \cdot{ }^{18,27,28,37}$ In the present study, we found a slightly better mean UIVA of $0.01 \log$ MAR compared with a mean UIVA ranging from 0.04 to $0.23 \log$ MAR in the available literature. Furthermore, most studies investigated the UIVA at $80 \mathrm{~cm}$, where some studies showed a better UIVA compared with the UIVA at $66 \mathrm{~cm}$. This might indicate that the ideal intermediate distance is slightly further from the object compared with the used measurement distance for intermediate vision in our study. In terms of UDVA (4 m), previous studies showed comparable results (ranging from 0.05 to -0.06 logMAR) to our findings (mean UDVA $-0.05 \operatorname{logMAR})$. However, for the near distance, a wider range was reported ( 0.01 to $0.27 \log \mathrm{MAR})$. For UNVA, we found a mean UNVA of $0.04 \pm 0.07$ logMAR, which is better compared with most clinical studies. The reported spectacle independence rates after bilateral implantation of the AT LISA tri 839MP ranged from 50 to $100 \%$. Our results showed a total spectacle independency of $54 \%$. However, only $15 \%$ of patients needed spectacles for longer than 1 hour a day. With respect to optical phenomena, previous studies showed an incidence of 60 to $84 \%$ of any type of halos and an occurrence of $7 \%$ to $25 \%$ of disabling halos. In terms of glare, $28 \%$ to $50 \%$ of patients 
Table 5. Continued.

\begin{tabular}{|c|c|c|c|c|c|c|}
\hline \multicolumn{2}{|c|}{ UNVA } & \multicolumn{2}{|c|}{ Halos (\%) } & \multicolumn{2}{|c|}{ Glare (\%) } & \multirow{2}{*}{$\begin{array}{c}\text { Total } \\
\text { Spectacle } \\
\text { Independence } \\
(\%)\end{array}$} \\
\hline Distance $(\mathrm{cm})$ & LogMAR & Any & Disabling & Any & Disabling & \\
\hline 40 & $0.20 \pm 0.12$ & NA & NA & NA & NA & NA \\
\hline 40 & $0.27 \pm 0.15$ & NA & NA & NA & NA & NA \\
\hline 40 & $0.27 \pm 0.15$ & NA & NA & NA & NA & NA \\
\hline 40 & 0.01 & NA & NA & NA & NA & 50 \\
\hline 40 & $0.13 \pm 0.05$ & NA & 7 & NA & 7 & 100 \\
\hline 40 & $0.15 \pm 0.14$ & 80 & 25 & 41 & 6 & $>90$ \\
\hline 40 & $0.04 \pm 0.10$ & 60 & NA & 28 & NA & 88 \\
\hline 40 & $0.05 \pm 0.08$ & NA & NA & NA & NA & $\leq 92$ \\
\hline 40 & $0.12 \pm 0.12$ & NA & NA & NA & NA & NA \\
\hline 40 & $0.12 \pm 0.12$ & NA & NA & NA & NA & NA \\
\hline 40 & $0.18 \pm 0.05$ & NA & NA & NA & NA & $<76$ \\
\hline 40 & $0.11 \pm 0.15$ & NA & NA & NA & NA & NA \\
\hline 40 & $0.11 \pm 0.15$ & NA & NA & NA & NA & NA \\
\hline 40 & $0.18 \pm 0.05$ & 70 & NA & 50 & NA & 67 \\
\hline 40 & $0.11 \pm 0.11$ & 84 & NA & 40 & NA & 88 \\
\hline 33 & $0.21 \pm 0.15$ & NA & NA & NA & NA & NA \\
\hline
\end{tabular}

experienced any form of glare, whereas $6 \%$ to $7 \%$ reported disabling glare complaints. Compared with our results, we see a higher incidence of disabling halos (39\% of patients) and a comparable incidence of disabling glare $(8 \%$ of patients).

In the current study, we used the SRD to test the functional reading ability after bilateral implantation of the TECNIS Symfony IOL or the AT LISA tri 839MP IOL. We used this device to test the visual acuity at $40 \mathrm{~cm}$ and $66 \mathrm{~cm}$ and at the preferred patient distance. Furthermore, the mean number of words per minute was reported. We found no significant differences between both groups in the words per minute at any distance. Notably, the preferred reading distance at the intermediate distance in the AT LISA tri 839MP group was on average larger compared with the initial tested intermediate distance of $66 \mathrm{~cm}$. These findings combined with the finding of better UIVA at $80 \mathrm{~cm}$ in the literature suggest that the ideal intermediate reading distance for the AT LISA tri $839 \mathrm{MP}$ is somewhere between $70 \mathrm{~cm}$ and $80 \mathrm{~cm}$. When we compare the mean UIVA and UNVA obtained with the reading charts and the SRD, we see some differences. Whereas the AT LISA tri 839MP group had a better, however not significantly different, UNVA compared with the Symfony group using the reading charts, the SRD showed a comparable mean UNVA of 0.08 logMAR for both groups. In contrast to the UNVA, both groups scored worse at the UIVA using the SRD compared with the reading charts. The slight difference between both groups remained stable compared with the difference measured with the reading charts.

Mesopic conditions are known to be a major factor, which may decrease visual acuity after bilateral implantation of a trifocal or extended depth-of-focus (EDOF) IOL. In the current study, we saw a significant decrease in visual acuity at all distances under mesopic conditions compared with photopic conditions for both groups. No statistically significant differences were seen comparing contrast sensitivity either under photopic or mesopic conditions, between groups. Furthermore, no differences were seen under mesopic conditions between both groups at any distance using reading charts or the SRD.

One of the limitations of the current study is the intraoperative astigmatism correction. Incisions on the steep axis or femtosecond laser-assisted arcuate incisions were performed peroperatively when indicated to correct preexisting corneal astigmatism. However, a total of $8 \%$ and $11 \%$ of eyes in the AT LISA tri 839MP and Symfony groups, respectively, had a residual cylinder of $1.5 \mathrm{D}$ or more. Furthermore, the chosen intermediate distance of $66 \mathrm{~cm}$ is uncommon compared with the current literature. Therefore, a good comparison between previous studies and the current data cannot be done. In addition, the AT LISA tri 839MP IOL is designed for an intermediate vision at $80 \mathrm{~cm}$. However, we believe that $66 \mathrm{~cm}$ might be a more commonly used working distance compared with the $80 \mathrm{~cm}$ used in previous studies. Another limitation is the lack of objective (optical bench) and psychophysical quantification of halos in this study. With regard to optical side effects, previous optical bench experiments showed a larger halo with 2 concentric rings (an outer, low-intensity ring and a small, high-intensity inner one) around the image of the pinhole for trifocal IOLs compared with bifocal IOLs. ${ }^{4}$ EDOF IOLs have fewer diffractive rings than trifocal IOLs. Yoo et al. ${ }^{38}$ showed in there optical bench study that the halo pattern of these EDOF IOLs was similar to that found in the monofocal IOL. However, another in vitro study showed halos with comparable intensities for EDOF, bifocal and trifocal IOLs. ${ }^{39}$ In the present study, the sample size 
was not powered for the secondary outcomes, such as halos and glare. Finally, although monovision was used for the Symfony group, no monocular performance or stereoacuity was measured. In respect to stereovision, we have not received subjective complaints of the patients.

In conclusion, the current study showed that bilateral implantation of both the TECNIS Symfony IOL and the AT LISA tri 839MP IOL results in good binocular uncorrected visual acuity at far, intermediate, and near distances. Targeting micromonovision when implanting the TECNIS Symfony IOL could be used to improve the UNVA and UIVA compared with targeting emmetropia in both eyes. Around $80 \%$ of patients in both groups were total spectacle independent or needed spectacles less than 1 hour a day. Mesopic conditions have an inadvertent effect on visual acuity at all distances for both IOL designs. The less common photopic phenomenon in both groups was glare, with only a low incidence of disabling amounts of glare. Disabling halos was seen in twice as many patients after bilateral AT LISA tri 839MP IOL implantation compared with bilateral Symfony IOL implantation; however no statistically significant difference was found. The functional reading ability was comparable between both groups. Nevertheless, more than $90 \%$ of patients would recommend the implanted IOL to family and friends.

Based on the current results, we can conclude that the TECNIS Symfony IOL is a good alternative to achieve postoperative spectacle independence with minimal use of additional reading spectacles in $20 \%$ of cases.

\section{WHAT WAS KNOWN}

- Trifocal intraocular lenses (IOLs) have the ability to increase postoperative spectacle independence for near, intermediate, and far distances compared with monofocal and bifocal IOLs.

\section{WHAT THIS PAPER ADDS}

- The Symfony Extended Range of Vision IOL, applied as micromonovision, improved intermediate vision further without significantly compromising reading ability or increasing optical side effects.

\section{REFERENCES}

1. De Silva SR, Evans JR, Kirthi V, Ziaei M, Leyland M. Multifocal versus monofocal intraocular lenses after cataract extraction. Cochrane Database Syst Rev 2016;12:CD003169

2. De Vries NE, Nuijts RM. Multifocal intraocular lenses in cataract surgery: literature review of benefits and side effects. J Cataract Refract Surg 2013; 39:268-278

3. Shen Z, Lin Y, Zhu Y, Liu X, Yan J, Yao KI. Clinical comparison of patient outcomes following implantation of trifocal or bifocal intraocular lenses: a systematic review and meta-analysis. Sci Rep 2017;7: 45337

4. Alba-Bueno F, Garzón N, Vega F, Poyales F, Millán MS. Patient-perceived and laboratory-measured halos associated with diffractive bifocal and trifocal intraocular lenses. Curr Eye Res 2018;43:35-42

5. Puell MC, Pérez-Carrasco MJ, Hurtado-Ceña FJ, Alvarez-Rementería L. Disk halo size measured in individuals with monofocal versus diffractive multifocal intraocular lenses. J Cataract Refract Surg 2015;41: $2417-2423$
6. Dominguez-Vicent A, Esteve-Taboada JJ, Anguila-Carrasco AJD, FerrerBlasco T, Mòntes-Micó R. In vitro optical quality comparison between the Mini WELL Ready progressive multifocal and the TECNIS Symfony. Graefes Arch Clin Exp Ophthalmol 2016;254:1387-1397

7. Esteve-Tabiada JJ, Domínguez-Vicent A, Ánguila-Carrasco AJD, FerrerBlasco T, Mòntes-Micó R. Effect of large apertures on the optical quality of three multifocal lenses. J Refract Surg 2015;31:666-672

8. Millán MS, Vega F. Extended depth of focus intraocular lens Chromatic performance. Biomed Opt Express 2018;8:4294

9. Dexl AK, Schlögel H, Wolfbauer M, Grabner G. Device for improving quantification of reading acuity and reading speed. J Refract Surg 2010; 26:682-688

10. Hirnschall N, Motaabbed JK, Dexl A, Grabner G, Findl O. Evaluation of an electronic reading desk to measure reading acuity in pseudophakic patients. J Cataract Refract Surg 2014;40:1462-1468

11. Attia MS, Auffarth GU, Khoramnia R, Linz K, Kretz FT. Near and intermediate reading performance of a diffractive trifocal intraocular lens using a reading desk. J Cataract Refract Surg 2015;41:2707-2714

12. Linz K, Attia MS, Khoramnia R, Tandogan T, Kretz FT, Auffarth GU. Clinical evaluation of reading performance using the Salzburg reading desk with a refractive rotational asymmetric multifocal intraocular lens. J Refract Surg 2016;32:526-532

13. Attia MS, Khoramnia R, Auffarth GU, Kirchner M, Holzer MP. Near and intermediate visual and reading performance of patients with a multifocal apodized diffractive intraocular lens using an electronic reading desk. J Cataract Refract Surg 2016;42:582-590

14. Attia MSA, Auffarth GU, Kretz FTA, Tandogan T, Rabsilber TM, Holzer MP, Khoramnia R. Clinical evaluation of an extended depth of focus intraocular lens with the Salzburg reading desk. J Refract Surg 2017;33:664-669

15. Steinberg EP, Tielsch JM, Schein OD, Javitt JC, Sharkey P, Cassard SD, Legro MW, Diener-West M, Bass EB, Damiano AM. The VF-14. An index of functional impairment in patients with cataract. Arch Ophthalmol 1994;112 630-638

16. Nijkamp MD, Nuijts RM, Borne B, Webers CA, van der Horst F, Hendrikse F. Determinants of patient satisfaction after cataract surgery in 3 settings. J Cataract Refract Surg 2000;26:1379-1388

17. Frost NA, Sparrow JM, Durant JS, Donovan JL, Peters TJ, Brookes ST. Development of a questionnaire for measurement of vision-related quality of life. Ophthalmic Epidemiol 1998;5:185-210

18. Mojzis P, Pena-Garcia P, Liehneova I, Ziak P, Alió L. Outcomes of a new diffractive trifocal intraocular lens. J Cataract Refract Surg 2014;40: 60-69

19. Pedrotti E, Bruni E, Bonacci E, Badalamenti R, Mastropasqua R, Marchin G. Comparative analysis of the clinical outcomes with a monofocal and an extended range of vision intraocular lens. J Refract Surg 2016;32:436-442

20. Cochener B. Clinical outcomes of a new extended range of vision intraocular lens: International Multicenter Concerto Study. J Cataract Refract Surg 2016;42:1268-1275

21. Ruiz-Mesa R, Abengózar-Vela A, Aramburu A, Ruiz-Santos M. Comparison of visual outcomes after bilateral implantation of extended range of vision and trifocal intraocular lenses. Eur J Ophthalmol 2017;27:460-465

22. Monaco G, Gara M, Di Censo F, Poscia A, Ruggi G, Scialdone A. Visual performance after bilateral implantation of 2 new presbyopia-correcting intraocular lenses: trifocal versus extended range of vision. $J$ Cataract Refract Surg 2017;43:737-747

23. Pedrotti E, Carones F, Aiello F, Mastropasqua R, Bruni E, Bonacci E, Talli P, Nucci C, Mariotti C, Marchini G. Comparative analysis of visual outcomes with 4 intraocular lenses: monofocal, multifocal, and extended range of vision. J Cataract Refract Surg 2018;44:156-167

24. Menucci R, Favuzza E, Caporossi O, Savastano A, Rizza S. Comparative analysis of visual outcomes, reading skills, contrast sensitivity, and patient satisfaction with two models of trifocal diffractive intraocular lenses and an extended range of vision intraocular lens. Graefe's Archive Clin Exp Ophthalmol 2018;256:1913-1922

25. Ganhesh S, Brar S, Pawar A, Relekar KJ. Visual and refractive outcomes following bilateral implantation of extended range of vision intraocular lens with micromonovision. J Ophthalmol 2018;2018:7321794

26. Kohnen T, Böhm M, Hemkeppler E, Schönbrunn S, DeLorenzo N, Petermann K, Herzog M. Visual performance of an extended depth of focus intraocular lens for treatment selection. Eye (Lond) 2019;33:1556-1563

27. Mojzis P, Majerova K, Hrckova L, Pinero DP. Implantation of a diffractive trifocal intraocular lens: one-year follow-up. J Cataract Refract Surg 2015; 41:1623-1630

28. Kretz FTA, Müller M, Gerl M, Gerl RH, Auffarth GU. Binocular function to increase visual outcome in patients implanted with a diffractive trifocal intraocular lens. BMC Ophthalmol 2015;15:110 
29. Marques EF, Ferreira TB. Comparison of visual outcomes of 2 diffractive trifocal intraocular lenses. J Cataract Refract Surg 2015;41: 354-363

30. Medicute J, Kapp A, Lévy P, Krommes G, Arias-Puente A, Tomalla M, Barraquer E, Rozot $P$, Bouchut $P$. Evaluation of visual outcomes and patient satisfaction after implantation of a diffractive trifocal intraocular lens. J Cataract Refract Surg 2016;42:203-210

31. Kohnen T, Titke C, Böhm M. Trifocal intraocular lens implantation to treat visual demands in various distances following lens removal. Am J Ophthalmol 2016;161:71-77

32. Bilbao-Calabuig R, Llovet-Rausell A, Ortega-Usobiaga J, Martinez-del Pozo M, Mayordomo-Cerdá F, Segura-Albentosa C, Baviera J, LlovetOsuna F. Visual outcomes following bilateral implantation of two diffractive trifocal intraocular lenses in 10084 eyes. Am J Ophthalmol 2017;179: 55-66

33. Kaymak H, Breyer D, Alió JL, Cochener B. Visual performance with bifocal and trifocal diffractive intraocular lenses: a prospective threearmed randomized multicenter clinical trial. J Refract Surg 2017;33: 655-662

34. Menucci R, Favuzza E, Caporossi O, Rizzo S. Visual performance, reading ability and patient satisfaction after implantation of a diffractive trifocal intraocular lens. Clin Ophthalmol 2017;11:1987-1993

35. Alió JL, Kaymak H, Breyer D, Cochener B, Plaza-Puche AB. Quality of life related variables measured for three multifocal diffractive intraocular lenses: a prospective randomised clinical trial. Clin Exp Ophthalmol 2018;46:380-388

36. Xiaomin L, Xie L, Huang Y. Comparison of the visual performance after implantation of bifocal and trifocal intraocular lenses having an identical platform. J Refract Surg 2018;34:273-280

37. Yang $Y, L v H$, Wang $Y$, Jiang $X$, Zhang M, Li X. Clinical outcomes following trifocal diffractive intraocular lens implantation for age-related cataract in China. Clin Ophthalmol 2018;12:1317-1324

38. Yoo YS, Whang WJ, Byun YS, Piao JJ, Kim DY, Joo CK, Yoon G. Throughfocus optical bench performance of extended depth-of-focus and bifocal intraocular lenses compared to a monofocal lens. J Refract Surg 2018;34: 236-243

39. Gatinel D, Loicq J. Clinically relevant optical properties of bifocal, trifocal, and extended depth of focus intraocular lenses. J Refract Surg 2016;32: 273-280

\section{OTHER CITED MATERIALS}

A. ClinicalTrials.gov Identifier: NCT03117426

B. https://www.surgical.jnjvision.com/iols/extended-depth-of-focus/tecnissymfony\#enhanced-functionality

Disclosures: Dr. Nuijts is a consultant at Alcon Laboratories, Inc., ASICO LLC, and Thea Pharma, and receives financial support for research from Abbott Medical Optics, Inc., Alcon Laboratories, Inc., Bausch \& Lomb, Inc., Carl Zeiss Meditec AG, Oculentis GmbH, and Ophtec BV. Dr. Bauer isa consultant for Alcon Laboratories, Inc. and Bausch \& Lomb, Inc.; receives financial support for research from Alcon Laboratories, Inc.; and receives lecture fees from Alcon Laboratories, Inc. and Bausch \& Lomb, Inc. None of the other authors has a financial or proprietary interest in any material or method mentioned.

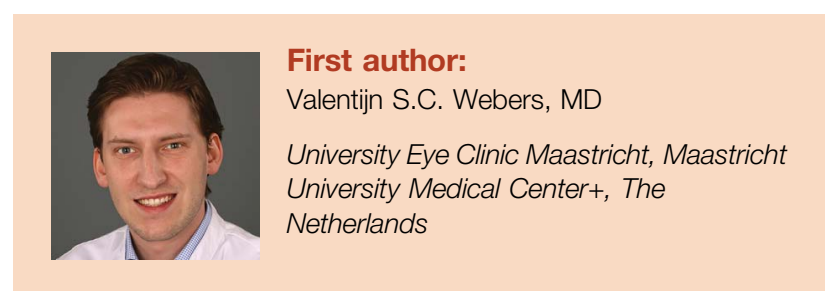

